\title{
The epidemiological transition: need to incorporate obesity prevention into nutrition programmes
}

\author{
Ricardo Uauy* and Juliana Kain \\ Institute of Nutrition and Food Technology (INTA), University of Chile, Casilla 138-1 1, Santiago, Chile
}

\begin{abstract}
Background: Trends in the nutritional status for developing countries that are undergoing rapid economic growth indicate a decrease in protein-energy malnutrition (PEM) with an associated rise in obesity prevalence.

Objective: This paper analyses how supplementary feeding programmes may contribute to rising obesity trends, what factors may explain this phenomenon, and potential strategies to avoid obesity in malnutrition prevention efforts.

Design and setting: This is a descriptive study of changes in nutritional status of infants and young children in Chile and the possible impact of supplementary feeding programmes on the rise in prevalence of obesity. We explored the changes in anthropometric indices before and after receiving food programme benefits and the use of targeting strategies as a way to combine the need to promote optimal growth while preventing obesity.

Results: Evaluation of the change in nutritional status from participants in Chilean supplementary feeding programmes has shown that targeting strategies have been inadequate as children mainly modify their weight-for-age and weight-for-height, while their length-for-age remains practically unchanged.

Conclusions: Monitoring length-for-age as well as weight-for-length is necessary to permit the identification of stunted overweight and obese children, as they should not be given excess energy. Energy supplementation should be adjusted according to activity level, securing adequate micronutrient density. PEM prevention programmes need periodic evaluation, including targeting of beneficiaries, definition of real needs and possible effect on obesity.
\end{abstract}

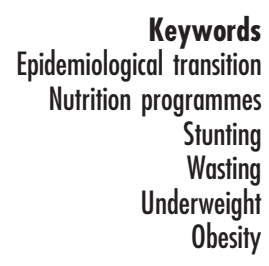

The purpose of this article is to analyse the apparently conflicting goals of obesity prevention and the continuing efforts to eradicate malnutrition. Trends in nutritional status for many developing countries undergoing rapid economic growth, especially those that have become heavily urbanised, indicate a decrease in malnutrition with an associated rise in the prevalence of obesity ${ }^{1}$. Moreover, most nutrition programmes addressing the prevention of malnutrition have built-in mechanisms that may easily promote excess energy intake and positive energy balance, and thus increase obesity. The combined objectives of promoting child growth while preventing obesity are not recognised as essential complements in most nutrition programmes. In some circumstances providing food to prevent malnutrition, without considering the need to prevent obesity, may do more harm than good.

The nature of the problem is exemplified in a simple manner in Fig. 1a, which presents the weight-for-age distribution of children in a typical developing country with a high prevalence of underweight children. As depicted in Fig. 1b, providing food for all children and not only those who are underweight will displace the whole curve to the right, generating a significant proportion of overweight and obese children. In contrast, Fig. 1c shows the desirable outcome if targeted efficiently; in this case the distribution of weight-for-age for the population is normal and very few individuals are underweight or obese. The evidence emerging from countries undergoing the epidemiological transition indicates that if food supplements are provided without careful targeting, the situation is similar to that depicted in Fig. 1b. Some planners may consider this phenomenon as an unavoidable consequence, while others even suggest this a desirable outcome, since it serves as evidence of a successful intervention ${ }^{2}$.

A critical issue in defining the nature of this problem is recognising that underweight children are usually stunted. Thus, most malnourished children will be of low weightand length-for-age, but will have a near normal weightfor-length/height; they are underweight and stunted, but not wasted. Since recovery in length-for-age is incomplete if nutrition improvement occurs after 24 to 36 months of age, these children - when given additional food - will gain significantly more weight-for-age than length-for-age. In older children, little or no gain in length-for-age is observed $^{3}$. In severe stunting, with delayed bone age maturation, stunting is potentially more reversible. We 


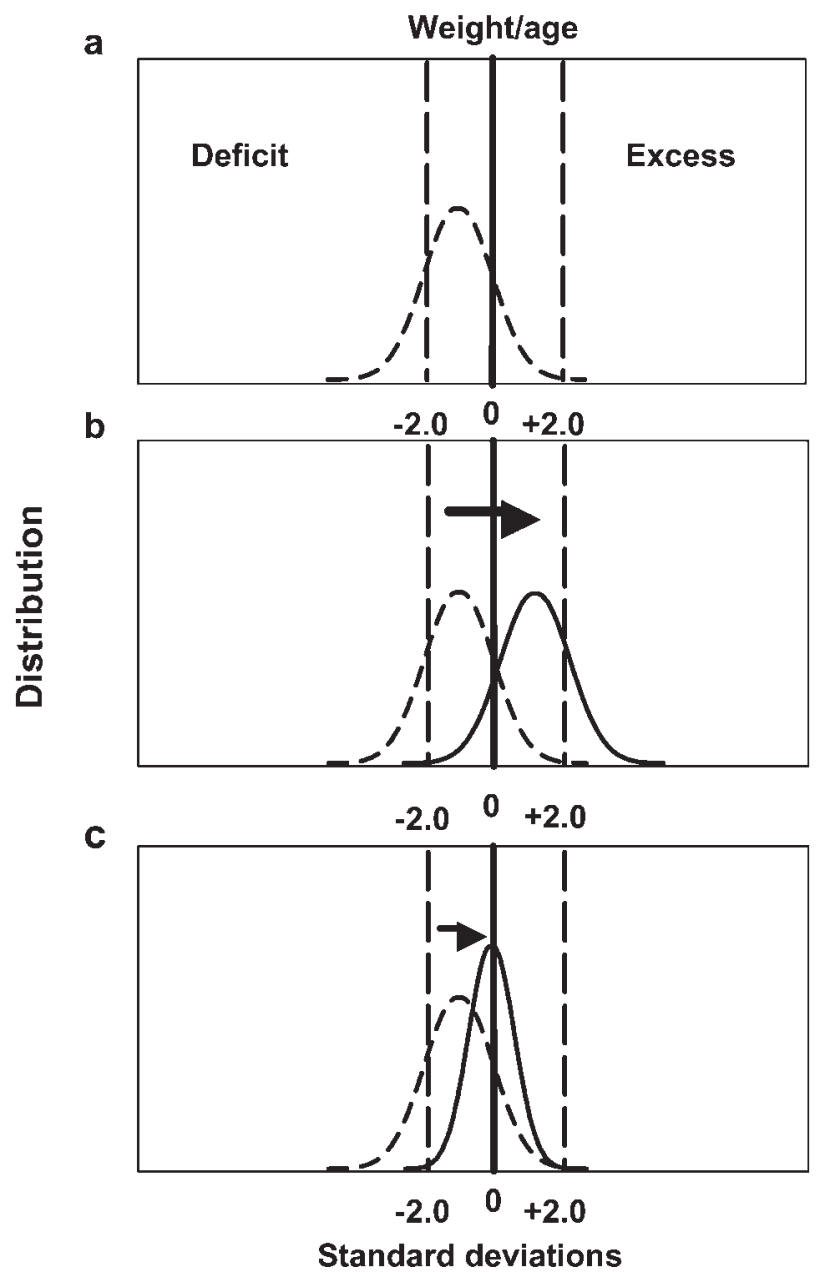

Fig. 1 (a) Distribution of weight-for-age in a population where PEM is prevalent (dotted line). (b) Change in the distribution after universal food supplementation (solid line), demonstrating elimination of PEM and increase in obesity. (c) Change in distribution after an ideally targeted intervention

shall exemplify these issues under various settings, where additional food energy is provided to children who are underweight, and evaluate the consequences in terms of obesity prevalence. We explore how supplementary feeding programmes may contribute to rising obesity trends, what factors may explain this phenomenon, and potential strategies to avoid a rise in obesity as a byproduct of malnutrition prevention efforts.

\section{Supplementary feeding: part of the solution and/or part of the problem}

A recent Food and Agriculture Organization (FAO) survey with data from 19 Latin American countries found that over $20 \%$ of the population - approximately 83 million people of an estimated 414 million in these countries - receive some level of food assistance benefits from nutritionrelated programmes ${ }^{4}$. In contrast, the number of malnourished in the countries studied was 10 million, $12 \%$ of the total beneficiaries. Most programmes do not have targeting criteria based on actual anthropometry, but rather on socio-economic conditions. The benefits are given to all, independent of whether there is evidence of low body weight. Nutrition programmes have evolved beyond the immediate needs of the malnourished and have become part of social and economic benefits demanded by populations living under poverty.

Significant reductions in underweight and wasting have occurred in most countries; undoubtedly supplementary feeding programmes have played an important role in this decline. Unfortunately, they may also have contributed to the rising trends in obesity ${ }^{5}$. Stunting remains a problem in most developing countries, despite the virtual eradication of wasting in many ${ }^{6}$. In this setting, providing food supplements may be beneficial for some, while it may be detrimental for others. Careful selection of beneficiaries for food assistance programmes and determining the right combination of nutrients/foods, education and lifestyle interventions that are required to optimise nutrition and health at each stage of the life cycle are crucial problems that should be addressed before initiating specific programmes ${ }^{7}$.

Chile is often presented as a paradigm of the success of supplementary feeding programmes. Indeed, there is a close association between the presence of these massive and expensive interventions and the decline in malnutrition in all age groups. Over the past decade this relationship has been lost, but the correlation with the rising obesity prevalence has become notable ${ }^{8}$. Examples from Chile will be given in an effort to show the potential impact that nutrition supplementation programmes may have on the prevalence of obesity and to signal the road ahead for other countries undergoing a rapid nutrition transition.

The Chilean Supplementary Feeding Program or 'Programa Nacional de Alimentación Complementaria' (PNAC), which began in the 1920s, has universal coverage secured by law and financed by direct contributions from the private and public sectors. In terms of beneficiaries, it has universal coverage, presently approximately 1.2 million children under 6 years of age and 200000 pregnant women. This corresponds to approximately $80 \%$ of the national population of infants under 2 years of age and $70 \%$ of pre-school children, pregnant women and nursing mothers. No specific targeting strategy is in place although self-exclusion of high-income beneficiaries does occur? The main objectives of PNAC are to:

- promote normal growth and development in children from conception through 6 years of age by providing food supplements to the mother during pregnancy and lactation, and to the child from birth to 6 years of age;

- protect the mother's health during pregnancy and lactation;

- promote breast-feeding by providing supplements to mothers during pregnancy and lactation; 
- prevent low birth weight related to maternal malnutrition, prevent infant and childhood malnutrition and improve coverage of primary health care activities, thus providing an incentive for beneficiaries to attend regular check-ups ${ }^{10}$.

Starting in 1983, two levels of benefits based on nutritional status were defined: the 'basic' PNAC, with universal coverage, and the 'enhanced' programme, which provides extra food to infants, children and pregnant and lactating women identified as being at risk for undernutrition or mildly undernourished. Assessment criteria included evaluating weight-for-length (or weight-forheight for those older than 2 years) and monthly rate of weight gain in two consecutive health visits, expressed as a percentage of that expected for their current age (based on the World Health Organization (WHO) standard). Biomedical risk was defined by one of two criteria: (1) undernourished - weight-for-length/height less than or equal to one standard deviation below $(\leq-1 \mathrm{SD})$ the WHO standard; and (2) growth faltering - weight-forlength $>-1$ SD and weight gain $<75 \%$ of expected for age (in two evaluations) for those under 2 years of age or $<50 \%$ for those over 2 years old. Children with poor weight gain, but classified as overweight based on weightfor-height $>+1 \mathrm{SD}$, were excluded from the 'enhanced' programme. The criterion for discharge from the 'enhanced' programme was having a weight increment $>75 \%$ of expected for those under 2 years of age and $>50 \%$ for those over 2 years old in three consecutive monthly visits. For those classified as undernourished, the same criterion of weight gain applied but, before discharge, children had to reach weight-for-length $>-1$ SD. The type of food provided was similar for both programmes, but the amounts were substantially greater for the 'enhanced' (i.e. $6 \mathrm{~kg}$ month $^{-1}$ vs. $2 \mathrm{~kg} \mathrm{month}^{-1}$ in the $0-11$-month-old group and $6 \mathrm{~kg}$ vs. $1 \mathrm{~kg}$ for the older ones). In addition, the latter also received rice, to benefit all family members and prevent loss of foods destined for infants. In 1990, the average annual cost (includes only cost of food) per beneficiary in the 'enhanced' programme was US\$ 100; this figure varied based on age but was twice that of the 'basic' programme. Seventeen per cent of all children were beneficiaries and most were selected in the 'biomedical risk' category, i.e. having either of the two conditions described above ${ }^{11}$.

In 1992 Kain et al. ${ }^{10}$ conducted an evaluation of the 'enhanced' programme, comparing anthropometric indices of participants at entry (average age was 10 months) and discharge from the programme 12 months later. At the time the children were targeted, their $Z$-score for average length-for-age was -0.67 , that for weight-for-age was -0.4 and for weight-for-length it was -0.1 . At discharge, these figures were $-0.59,-0.17$ and +0.3 , respectively (Fig. 2). Analysis of changes in length-for-age ${ }^{12}$ demonstrated a small non-significant gain in length, while weight-for-age and weight-for-length increased significantly. What is clear from this evaluation is that if additional food is provided to mildly stunted children, they will gain weight to exceed the median reference value. The use of rate of weight gain and setting a $-1 S \mathrm{SD}$ cut-off in weight-for-length to define beneficiaries of the 'enhanced' programme contributed to the effectiveness of the programme in terms of identifying every child potentially at risk for undernutrition, contributing to the continued decline in undernutrition rates. On the other hand, feeding mildly stunted children may have contributed to the rise in overweight and obesity observed among pre-school children during the past decade. In summary, the weight gain criteria proved to be extremely

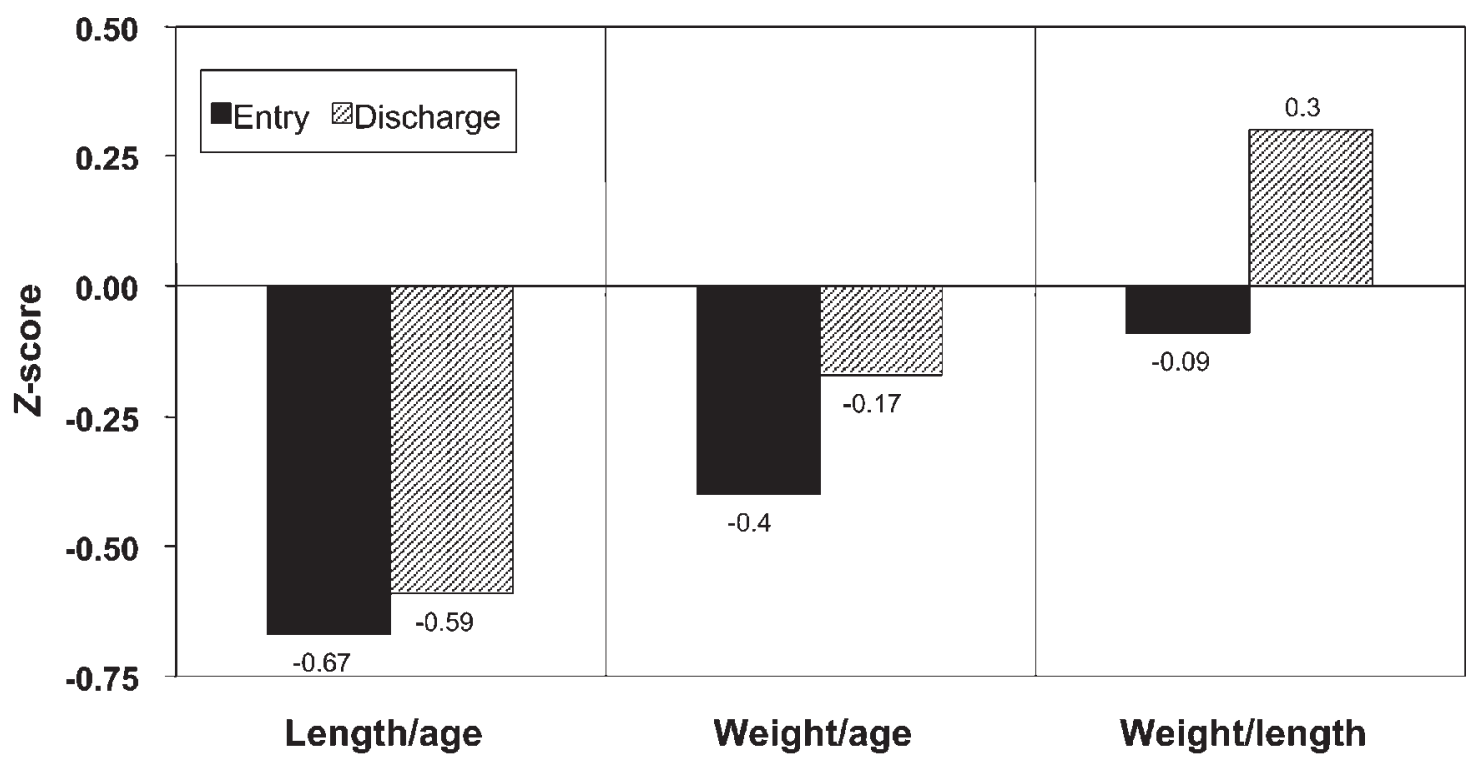

Fig. 2 Z-score at entry and discharge from the programme. Sources: Kain et al. ${ }^{10,12}$ 
sensitive, but not very specific, in determining who needed extra food, based on changes in weight-for-length after participating in the programme.

The limited impact of the 'enhanced' programme and its high cost served to support the modification of the targeting strategy in 1994. It is important to note that, at the time, the prevalence of children under 6 years with a weight-for-height $<-1 \mathrm{SD}$ of the WHO reference was only $3 \%$ and while for weight-for-age $<-1 \mathrm{SD}$ of the WHO reference the prevalence was $9 \%{ }^{12}$. As a result of the careful evaluation, a new targeting strategy started in 1994 established two categories: (1) undernutrition and (2) at risk for undernutrition, defined on the basis of international anthropometry guidelines; it includes an age cutoff in the anthropometric criteria used. Children under 2 years of age are defined as undernourished if weight-forage is $\leq-2 \mathrm{SD}$ of the WHO reference, while for children over 2 years old the definition is weight-for-height $\leq-2 \mathrm{SD}$. These modifications were justified in the older children; i.e. if weight-for-height $\leq-1 S \mathrm{SD}$ is used as a cutoff limit, a large proportion of stunted children behave as false positives - their growth does not improve with added food. This new definition significantly reduced the prevalence figures of undernourished children to less than $1 \%$. Children at risk for undernutrition were redefined with the same age cut-off as follows: (1) for under 2 years of age, risk was defined by a weight-for-age between -1 and $-2 \mathrm{SD}$; and (2) for those older than 2 years, weight-forheight between -1 and -2 SD was used. Presently, discharge criteria for children classified as undernourished is a weight-for-length greater than -1SD of the WHO reference for three consecutive months, while those at risk for undernutrition are discharged if weight-for-age is above $-2 \mathrm{SD}$ and weight-for-length is greater than $-1 \mathrm{SD}$ at the end of a three-month trial period. In this latter category, children cannot exceed 6 months per year in the programme, even if anthropometry does not improve ${ }^{13}$.

Figure 3 shows the effect produced by changing the targeting criteria on the proportion of children who are beneficiaries of the enhanced PNAC, by age group. A significant decline in percentage of targeted children occurs in all cases, except with the 5-month-old group. Using the same set of data, 11\% of the total group under 6 years of age were classified as undernourished or 'at risk for undernutrition' with the old criteria, compared with $5.8 \%$ with the new criteria; i.e. a $47.3 \%$ decline. The greatest decline was observed in the 24-72 month category $^{14}$.

A separate example is drawn from the National Nursery Schools Council Program (JUNJI). It was created in 1971 under the Ministry of Education to provide childcare as well as supplementary food for low-income toddlers and pre-schoolers. Coverage is close to $70 \%$ of those in need. In 1998, approximately 100000 children under 5 years of age attended JUNJI. Of those, 95\% were pre-schoolers from 2 to 5 years of age; the rest were infants under 2 years old. The food distributed is programmed to cover $58-75 \%$ of children's daily energy needs, depending on whether they attend a half or a full day. The energy supplied by age grouping is: (1) under 12 months, $800 \mathrm{kcal}$; (2) 12 to 24 months, $950 \mathrm{kcal}$; (3) 2 to 3 years, $950 \mathrm{kcal}$; and (4) 3 to 5 years, $1000 \mathrm{kcal}$. If a nutritional deficit is detected, a reinforcement of $150 \mathrm{kcalday}^{-1}$ is provided ${ }^{15}$. This programme most likely has contributed to the notable decline in underweight and stunting observed in the preschool population during the past decade, but is probably associated with the increase in obesity rates. In fact, an evaluation of the change between March (school

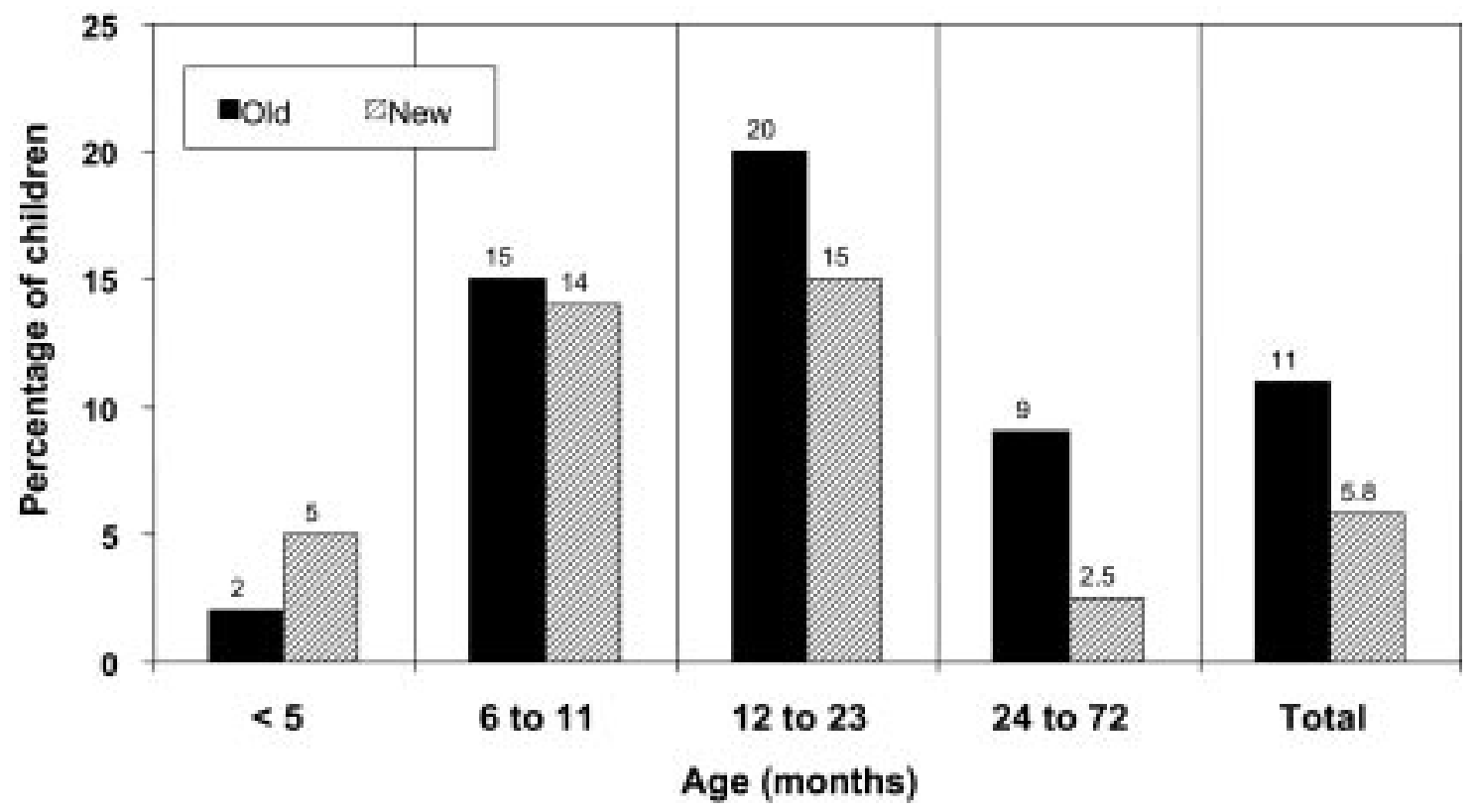

Fig. 3 Percentage of children selected based on old and new targeting criteria 
entrance) and November (final month of the school year) in the prevalence of nutritional deficits and excesses, using 1SD as a cut-off, showed that length-for-age remained unchanged while prevalence of low weight-for-age and weight-for-height declined well under the expected. On the contrary, indices of excess defined as weight-forheight $>1$ SD and 2SD showed a marked increase. Also, a retrospective analysis of 8086 children who attended JUNJI for three consecutive years showed a threefold increase in obesity prevalence over the observation period, rising from $5 \%$ to $15 \%$, using 2SD of weight-for-length using the National Center for Health Statistics (NCHS)-WHO criteria ${ }^{2}$.

Recent studies conducted by Cardona et al. ${ }^{16}$, using doubly labelled water, have demonstrated that children attending the JUNJI programme expend about $1400 \mathrm{kcal}$ per day, while that recommended, based on weight using FAO/WHO equations for age and gender, is $1600 \mathrm{kcal}$ per day. This demonstrates an overestimation of $200 \mathrm{kcal}$ per day. During their eight hours' stay at the JUNJI centre, they received $1000 \mathrm{kcal}$ rather than the approximately $800 \mathrm{kcal}$ (at most) they spend over this period based on measured physical activity while in the centre. Thus, a positive balance of approximately $50-100 \mathrm{kcal}$ may accumulate, unless the children were underfed and/or overactive at home. Unfortunately, data from similar children studied by Rebolledo et al. $^{17}$ demonstrated that most of those attending the centres received two to three additional meals at home; $72 \%$ ate double breakfast and $42 \%$ had a double afternoon snack. Moreover, sedentary lifestyles predominate, including an average of three hours of daily TV viewing ${ }^{18}$. In summary, these children are likely overfed at home and sedentary, enhancing the chance for excess energy intake and positive energy balance. A daily excess of 50-100 kcal over the 200 days per year of mean school attendance implies a positive balance of 10-20 thousand kcal; a total of around $2 \mathrm{~kg}$ of extra fat would be stored per year.

The influence of stunting in raising the prevalence of obesity, given the effect of short stature on body mass index (BMI) and energy balance, needs to be considered ${ }^{19,20}$. Stunted children have less lean body mass; thus total energy expenditure is lower. In addition, recent studies indicate that fasting fat oxidation is reduced by about $10 \%$ in stunted children $^{21}$. We have observed a drop in stunting rates in Chile concomitant to the rise in obesity. Thus, the contribution of stunting to the rise in obesity prevalence has decreased over time, suggesting that other factors are responsible for the rising obesity trends. The prevalence of stunting (height-forage $<-2 Z$, WHO) in 6-year-olds was $10.6 \%$ and $7.3 \%$ for boys and girls, respectively, in 1987, while in 1996 these figures declined to $5.8 \%$ and $3.4 \%$. In fact, the average stature in this age group increased by $2 \mathrm{~cm}$ during the 10 -year period considered $^{22}$.

If we examine the prevalence of obesity in stunted vs. those with normal height in 6-year-olds in 1987, we find that stunted boys and girls have higher obesity prevalence.
For stunted boys, obesity (weight-for-height $>2 Z$, WHO) was $10.5 \%$, while for those of normal height, it was $6 \%$; for stunted girls, obesity was $12.2 \%$, while in those of normal height, it was 7.4\%. In 1996, when the prevalence of stunting had decreased and obesity increased, stunting was less strongly associated to increased risk of obesity. In fact, the odds ratio (OR) for obesity in the stunted in 1987 was 1.83 (confidence interval (CI) 1.72-1.94) and 1.74 (1.62-1.86) in boys and girls, respectively, while in 1996, these figures were 1.34 (1.26-1.43) and 1.61 (1.5-1.74). These data suggest that stunting is associated with a higher risk of obesity, but as stunting decreases, short stature becomes less significant as a risk factor for obesity. In fact, in populations of normal height, obesity in children is associated with increased stature ${ }^{23}$, most likely secondary to enhanced bone age maturation.

The observations in infants, young children and adolescents serve to document the antecedents for the observed rise in adult obesity, especially in those of low socio-economic status in Chile (see Albala et al. ${ }^{24}$ ).

\section{Factors that explain the effect of nutrition programmes in rising obesity trends}

Universal feeding programmes will promote obesity Unless underweight is universal, targeting strategies are needed to prevent obesity in those who are not underweight. It is important to remember that when the mean population energy intake is equivalent to $100 \%$ of the energy allowance, $50 \%$ of the individuals in a population will exceed their energy requirement. Providing additional energy to all may promote obesity in those who are sedentary and do not increase their physical activity. Targeting is thus mandatory to prevent obesity. The only clear-cut criterion is to select beneficiaries based on being wasted (low weight-for-length/height) and weight-for-age in infants under a year of age, since in early life, inadequate energy intake may compromise linear growth ${ }^{25}$. To enhance sensitivity of the targeting in children over 12 months of age, weight-for-age may be used for the initial selection of beneficiaries; but if in the course of the programme an infant exceeds median weight-for-length, supplementation should be discontinued.

\section{Feeding underweight/stunted children}

As socio-economic conditions improve and the diet gains in energy supply, stunting rather than underweight remains the most prevalent problem. Under these conditions, food supplementation of underweight children may induce weight gain, while length deficit may not be reversed. If protein-energy malnutrition (PEM) prevention programmes are targeted on the basis of low weightfor-age, children with length deficit may become obese (high weight-for-length) while remaining underweight. Figures $4 \mathrm{a}$ and $4 \mathrm{~b}$ depict this phenomenon, while Fig. 4c 

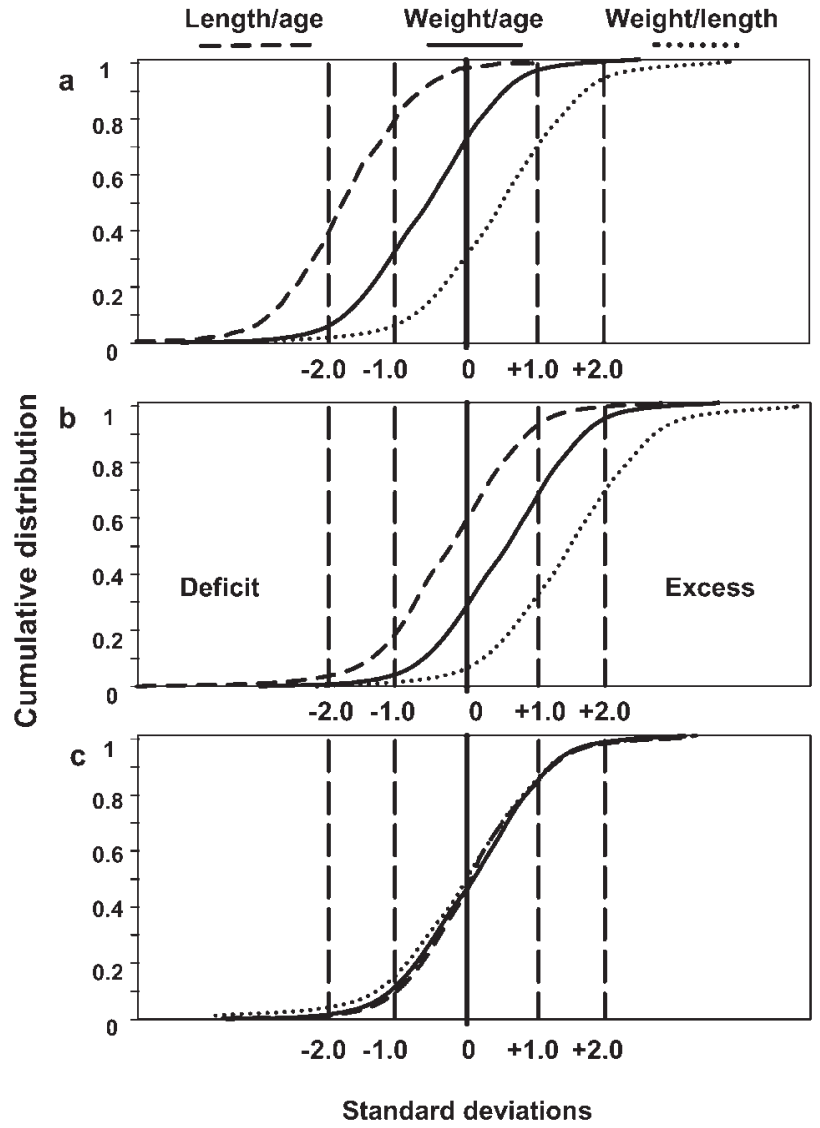

Fig. 4 (a) Cumulative distributions of anthropometric indices in a population where stunting is common. (b) Change observed in distributions as stunting improves after successful implementation of supplementary feeding programme; note the increase in obesity. (c) Desired change in distributions as stunting declines, if ideal linear growth promotion and obesity prevention are in place

shows the desired change. Stunted infants have lower basal energy expenditure and less lean body mass relative to age-matched controls and thus have lower energy needs than normal children ${ }^{26}$. This should be considered in defining the energy provision in supplementary feeding programmes, especially in the urban setting. These considerations also apply for older children and adults.

\section{Feeding micronutrient-poor foods}

Most PEM prevention programmes use food supplements that provide ample energy and protein but may be deficient in micronutrients such as zinc ( $\mathrm{Zn}$ ), iron ( $\mathrm{Fe}$ ), vitamin $\mathrm{A}$ and essential fatty acids (EFAs), thus limiting linear growth ${ }^{27}$. Complementary foods provided for young children and pregnant women are usually based on cereals or cereal/legume mixes. Wheat/soy or corn/soy blends are typically used in food aid; sometimes milk proteins, skimmed milk, casein or whey, or other low-cost plant proteins are added. All of these are poor in Zn, vitamin A and Fe; moreover, micronutrient bioavailability in these foods may be low because of phytates, fibre or other plant food components. Milk and other dairy products are of limited value as providers of $\mathrm{Zn}, \mathrm{Fe}$ and EFAs; thus, unless fortified, they are ineffective in securing these nutrients for optimal growth. The need to improve the micronutrient content of foods used in supplementation has been recognised only recently; effective fortification strategies for local complementary foods are presently being developed and tested. Appropriate food-based programmes that depend on the consumption of fresh foods have never been implemented on a wide scale, but remain the desired approach and yet are difficult to implement. It has been well demonstrated that the provision of protein and energy without providing critical micronutrients may improve weight but not length, thus they will promote adipose tissue gain and obesity. This, in fact, may contribute to the association of stunting and obesity.

\section{Feeding energy-rich foods promotes excess energy} intake and positive energy balance

In most cases PEM prevention programmes use highfat/energy-dense diets in an attempt to compensate for low intake at home. This may lead, in some cases, to an energy intake from supplemental food that exceeds energy needs. In other situations children may become beneficiaries of multiple programmes, thus total energy intake exceeds real needs. In summary, food programmes that do not adequately consider total dietary intake and assume low energy intakes will promote excess intake and an overall positive energy balance ${ }^{28}$.

\section{Programmes that fail to adapt to changing conditions}

Nutrition programmes have enormous difficulties in responding to changing conditions; urbanisation and dietary change create new scenarios that are often ignored. Most PEM prevention programmes do not have systematic monitoring and evaluation or redesign as part of the ongoing planning process. Human resources at all levels, from field workers to policy makers, are slow to recognise the need for change, and have difficulties implementing change. In most cases, professionals responsible for programme implementation become the true stakeholders; they may fear losing their role or even their jobs if PEM is no longer a problem. Few, if any, professionals are willing to advocate for a reduction of nutrition programmes unless obesity is recognised as a major public health problem. Obesity may be seen as a sign of accomplishment in the fight against malnutrition, rather than a problem.

\section{Conclusions}

PEM prevention programmes should include monitoring not only of weight-for-age, but also of length-for-age as well as weight-for-length. These should permit identification of the stunted overweight or obese child. Beneficiaries should not be selected based solely on socioeconomic conditions, but on true assessment of nutritional 
status. Stunted children of low weight-for-age but normal weight-for-length should not be given excess energy, since this will lead to obesity. The quality of the foods provided is crucial in pre-school and school feeding programmes; fruits and vegetables should be included in the diet of children to provide micronutrients and prevent energy excesses. Obesity prevention requires optimising linear growth and lean tissue mass gain; thus micronutrients and quality of the protein source are important.

PEM prevention programmes need a periodic evaluation, including targeting of beneficiaries, definition of real needs and impact on obesity. Food products may need to be modified in urban settings. For example, in situations where stunting and obesity coexist, providing Fe- and Znfortified skimmed milk in pre-school feeding programmes, rather than full-fat products, is highly recommended. Programmes should be redesigned on the basis of actual need, considering the rapid transition of most urban communities in developing countries. Planners should consider the assessment of physical activity; if low, increased activity should be promoted.

Food programmes designed to combat PEM may become outdated as rapid improvements in socioeconomic and environmental conditions occur. Slashing social benefits without redirecting them is always unpopular. Instead, policy makers should reallocate these funds to alternative social programmes that enhance the quality of life of the poor. Thus, the changes will not be seen as taking away benefits from the poor, but rather as responding to a new situation where other needs become more relevant. Ideally the right to food should be upheld by providing access to safe and nutritious foods, based on what people can buy or grow for themselves.

\section{References}

1 Popkin BM. The nutrition transition and its health implications in lower-income countries. Public Health Nutr. 1998; 1: 5-22.

2 Uauy R, Albala C, Kain J. Obesity trends in Latin America: transiting from under to overweight. J. Nutr. 2001; 131: 893S-99S.

3 Martorell R. Results and implications of the INCAP Follow-up Study. J. Nutr. 1995; 125: 1127S-38S.

4 Peña M, Bacallao J. Obesity among the poor: an emerging problem in Latin America and The Caribbean. In: Peña M, Bacallao J, eds. Obesity and Poverty. A New Public Health Change. Scientific Publication No. 576. Washington, DC: Pan American Health Organization, 2000.

5 Albala C, Vio F. Epidemiological transition in Latin America: the case of Chile. Public Health 1995; 109: 431-42.

6 Administrative Committee on Coordination Sub-committee on Nutrition (ACC/SCN) and International Food Policy Research Institute (IFPRI). 4th Report on the World Nutrition Situation. Geneva: ACC/SCN, January 2000.

7 Albala C, Vio F, Kain J, Uauy R. Nutrition transition in Latinamerica: the case of Chile. Nutr. Rev. 2001; 59: 170-6.

8 Kain J, Burrows R, Uauy R. Obesity trends in Chilean children and adolescents. In: Obesity in Childhood and Adolescence. Nestlé Nutrition Workshop Series [in press].

9 Chilean Ministry of Health. Manual of the National
Supplementary Feeding Program (PNAC). Santiago: Chilean Ministry of Health, 1988.

10 Kain J, Vial I, Muchnik E, Contreras A. An evaluation of the enhanced Chilean Supplementary Feeding Program. Arch. Latinoam. Nutr. 1994; 44: 242-50.

11 Kain J, Uauy R. Targeting strategies used by the Chilean National Supplementary Feeding Program. Nutr. Res. 2001; 21: $677-88$.

12 Kain J, Pizarro F. Effect of an enhanced supplementary feeding program on infants length. Arch. Latinoam. Nutr. 1997; 47: 101-4.

13 Chilean Ministry of Health. Manejo Ambulatorio del Niño con Malnutrición. Santiago: División Programa de las Personas, 1994.

14 Torche A, Muchnik E, Atalah C, Vial I. Study of the Economic Evaluation of the National Supplementary Feeding Program. Final Report to the Ministry of Health, Santiago, 1995.

15 Uauy R, Riumallo J. Work Plan in Support of Guidelines on Formulating and Implementing Nutrition Programs (FINP) at the Country Level: Case Study. Chile: Food and Agriculture Organization, 1997.

16 Cardona O, Salazar G, Díaz E. Medición del gasto energético y patrón de actividad física de los niños asistentes a JUNJI. Tesis para optar al Grado de Magíster en Nutrición Humana INTA, Santiago, 2001.

17 Rebolledo A, Atalah E, Herrera P, Araya H, Castillo C. Hábitos alimentarios de preescolares de INTEGRA. Rev. Chil. Nutr. 1996; 24: 43.

18 Kain J, Andrade M. Characteristics of the diet and patterns of physical activity in obese Chilean preschoolers. Nutr. Res. 1999; 19: 203-15.

19 Schroeder D, Martorell R. Fatness and body mass index from birth to young adulthood in a rural Guatemalan population. Am. J. Clin. Nutr. 1999; 70(Suppl.): 137S-44S.

20 Trowbridge FL, Marks JS, Lopez de Romana G, Madrid S, et al. Body composition of Peruvian children with short stature and high weight-height. II. Implications for the interpretation for weight for height as an indicator of nutritional status. Am. J. Clin. Nutr. 1987; 46: 411-8.

21 Hoffman D, Sawaya A, Verreschi I, Tucker K, Roberts S. Why are nutritionally stunted children at increased risk of obesity? Studies of metabolic rate and fat oxidation in shantytown children from Sao Paulo, Brazil. Am. J. Clin. Nutr. 2000; 72: 702-7.

22 Kain J, Uauy R, Díaz M, Aburto A. Height increases in schoolchildren entering first grade during the last decade. Rev. Med. Chil. 1999; 127: 539-46.

23 Bellizzi M, Dietz W. Workshop on childhood obesity: summary of the discussion. Am. J. Clin. Nutr. 1999; 70: 173S-5S.

24 Abala C, Vio F, Kain J, Uauy R. Nutrition transition in Chile: determinants and consequences. Public Health Nutr. 2002; 5 $123-8$.

25 Martorell R, Kettel-Khan L, Schroeder D. Reversibility of stunting: epidemiological findings in children from developing countries. In: Causes and Mechanisms of Linear Growth Retardation [special issue]. Eur. J. Clin. Nutr. 1993: 48; S45-S57.

26 Karlberg J, Jalil F, Lam B, Low L, Yeung C. Linear growth retardation in relation to three phases of growth. In: Causes and Mechanisms of Linear Growth Retardation [special issue]. Eur. J. Clin. Nutr. 1993; 48: S25-S44.

27 Golden MHN. The role of individual nutrient deficiencies in growth retardation of children, as exemplified by zinc and protein. In: Waterlow JC, ed. Linear Growth Retardation in Less Developed Countries. Vevey: Nestlé Nutrition/New York: Raven Press, 1988; 143-64.

28 Rojas J, Uauy R. Need to prevent obesity without neglecting the protection of children at risk of malnutrition. Rev. Chil. Nutr. 1999; 26: 35-39. 